Magna Scientia Advanced Research and Reviews

eISSN: 2582-9394

Cross Ref DOI: $10.30574 / \mathrm{msarr}$

Journal homepage: https://magnascientiapub.com/journals/msarr/

(REVIEW ARTICLE)

\title{
Clinical characteristics and the main symptoms of coronavirus disease SARS and MERS: A descriptive minireview
}

\author{
Fatma Mustafa Muhammad *and Chateen Izaddin Ali Pambuk* \\ College of Dentistry; Department of Basic Science; University of Tikrit; Iraq.
}

Magna Scientia Advanced Research and Reviews, 2021, 02(02), 116-118

Publication history: Received on 12 July 2021; revised on 28 August 2021; accepted on 30 August 2021

Article DOI: https://doi.org/10.30574/msarr.2021.2.2.0064

\begin{abstract}
Coronavirus is one of the viral diseases, and it expresses a severe and acute respiratory syndrome accompanied by a severe rise in body temperature, and acute lower respiratory infection, and there are several types of corona virus, including the virus that causes Middle East respiratory syndrome. for short (MERS), severe acute respiratory syndrome, and the new coronavirus 2019 (2019-nCoV). Symptoms of the disease can be distinguished: Pain in the joints of the body. general fatigue headache. Sore throat. Visibly elevated body temperature. Cough and difficulty breathing. Severe inflammation and damage to the alveoli. Swelling of lung tissue. Kidney failure if symptoms worsen. The aim of this descriptive minireview, generally, is to shed light on the main clinical characteristics and the main symptoms of Coronavirus disease SARS and MERS.
\end{abstract}

Keywords: Clinical characteristics; Symptoms; Coronavirus; SARS; MERS

\section{Introduction}

Coronas are a large family of viruses that can cause illnesses from the common cold to severe acute respiratory syndrome (SARS). Middle East Respiratory Syndrome (MERS) is a viral disease of the respiratory system caused by the Coronavirus (MERS-COV), which was first known in the Kingdom of Saudi Arabia in 2012. Although the vast majority of human cases of MERS virus have been attributed to human-to-human infection, it is likely that the main reservoir of this virus is camels, however, the exact role of camels in the transmission of the virus and the exact method of transmission is unknown. The virus that causes MERS does not appear to be easily transmitted from person to person without close contact, such as when unprotected care is given to a patient $[1,2]$.

Corona causes up to $30 \%$ of common colds. This virus infects many different types of living organisms. There are seven known human coronas. SARS spread in China and infected thousands of people in 37 countries, killing 774 people. Unlike MERS, SARS infection can spread easily among people living in the same household through respiratory droplets that come in contact with the skin or mucous membranes (eyes, mouth, or nose). During the SARS outbreak of 2003, approximately $25 \%$ of patients developed severe respiratory failure and $10 \%$ of patients died overall, and the SARS outbreak of 2002-2003 was controlled using only public health preventive measures, such as wearing surgical masks, washing Hands well, and isolate infected patients [1,2].

\section{Middle East respiratory syndrome}

The Middle East Respiratory Syndrome, which is caused by one of the types of corona virus, is a disease that may affect all ages, which occurred for the first time in Jordan in April 2012, and was registered for the first time by health sector

\footnotetext{
* Corresponding author: Chateen Izaddin Ali Pambuk and Fatma Mustafa Muhammad; E-mail: dr.chatin2@yahoo.com College of Dentistry; Dept. of Basic science; University of Tikrit; Iraq; ORCID ID : https://orcid.org/0000-0002-9893-8085 
officials in September of 2012 in the Kingdom of Saudi Arabia, where most of the cases of this syndrome were associated with travel or residence in the countries of the Arabian Peninsula or the surrounding areas. In most cases, the incubation period for the disease - which is the time between exposure to infection and the appearance of symptoms - ranges from five to six days, but in some cases it may also range from two to twelve days $[1,3]$.

\section{Middle East respiratory syndrome symptoms and complications}

Some symptoms may appear in people with Middle East respiratory syndrome, and symptoms can be divided into respiratory symptoms and digestive symptoms as follows: Respiratory symptoms: People with Middle East respiratory syndrome often suffer from severe respiratory symptoms, including: Fever, cough, shortness of breath. Gastrointestinal symptoms: People with Middle East Respiratory Syndrome may also have symptoms related to the digestive system (Gastrointestinal Tract), and these symptoms include: Diarrhea, Feeling nauseous and Vomiting $[3,4]$.

\subsection{Symptoms of acute respiratory syndrome}

Severe acute respiratory syndrome began to appear in China in 2003 and spread over the course of a year to more than 37 countries around the world, until it was controlled in 2012. The danger of severe acute respiratory syndrome lies in the possibility of developing some serious health complications for those infected: such as its ability to infect both parts of the respiratory system; Upper and lower extremities, thus increasing the chance of suffering from acute pneumonia, gastroenteritis, lung failure, heart failure, and liver failure, and it also caused death in $9.6 \%$ of those infected. It should be noted that these complications were less common in children when compared to affected adults. The following is a list of some of the symptoms and signs that appear when you have severe acute respiratory syndrome: High temperature Dry cough Cold and chills Diarrhea Difficulty breathing Feeling aches in the body $[1,3,4,5]$.

\subsection{Corona symptoms appearance}

Symptoms of infection begin to appear 2-14 days after exposure to the virus, and the disease can be distinguished by the following symptoms: Pain in the joints of the body. general fatigue headache. Sore throat. Visibly elevated body temperature. Cough and difficulty breathing. Severe inflammation and damage to the alveoli. Swelling of lung tissue. Kidney failure if symptoms worsen. Corona disease may lead to death in case of neglect and exacerbation of symptoms; Because the virus that causes the disease prevents oxygen from reaching the blood, causing a deficiency in the activities of the body's organs $[3,5]$.

\section{Phases of Corona disease}

The three phases of corona disease can be explained as follows: The first phase: It is the first week of infection, and its most prominent symptoms are: fever, muscle pain, and other general symptoms whose severity decreases after a few days. The second phase: It is the second week of infection with the disease, and the most prominent symptoms are: the lack of oxygen in sufficient quantities throughout the body, and a disturbance in the radiological picture. The third stage: which extends after the second week, and the patient at this stage needs to use artificial respiration; Because he couldn't breathe normally [2].

\section{Transmission of Corona virus}

Although corona viruses are present and effective throughout the year, the rate of infection increases during the winter and autumn seasons mostly, and in fact, most individuals are exposed to infection with one of the corona viruses especially the common ones - at least once during their life, and are considered viruses Corona is highly contagious and it is possible for an individual to contract it more than once throughout his life; Where it is believed that genetic changes and mutations in these viruses are the reason for the nature of severe infection, and it is worth noting that the infected person should avoid transmitting the infection to the non-infected, by staying indoors during the period of symptoms, avoiding close contact with others, and making sure to cover the mouth. And the nose during sneezing or coughing, and maintaining hygiene by getting rid of all used tissues, and the following are the most prominent ways of transmission of corona viruses: The scattering and spread of droplets containing the Corona virus when a patient sneezes or coughs without covering his mouth well. Touching or shaking hands with a person infected with the Corona virus. Touching surfaces and objects that have previously been exposed to respiratory fluids of a person infected with the Coronavirus, and then touching the nose, mouth, or eyes. The transmission of the Corona virus through contamination with the feces of an infected person, and it is a rare case $[6,7]$. 


\section{Corona virus spread}

There are many ways in which the virus spreads because of the ease and speed of its spread, it may spread through the transmission of sneezing droplets from an infected person to a healthy person, or by touching my hands to places and surfaces contaminated with the virus, or through the use of personal tools for the injured, such as using the same pillows or bed covers [2].

\section{Corona virus prevention}

The World Health Organization has warned employees in the health services sector of the need to take all measures to prevent the spread of the virus, in addition to the importance of reporting when an infection is suspected, and following the following steps to prevent its spread: Avoid approaching people who are likely to be infected with the virus. Do not use the things of the injured person. The necessity of washing hands with soap and water and disinfectant when in contact with an infected person. Wearing protective masks over the mouth and nose, in addition to wearing special rubber gloves when providing health care to patients. Maintain sterilization and cleanliness of surfaces $[6,7,8]$.

\section{Conclusion}

MERS and SARS severe acute respiratory syndrome, and the new coronavirus 2019 (2019-nCoV) symptoms of the disease can be distinguished by: Pain in the joints of the body. general fatigue headache. Sore throat. Visibly elevated body temperature. Cough and difficulty breathing. Severe inflammation and damage to the alveoli. Swelling of lung tissue. Kidney failure if symptoms worsen.

\section{Compliance with ethical standards}

\section{Acknowledgments}

Many thanks are going to Asst. Prof. dr. Chateen I Ali Pambuk for the spectacular aiding and writing in the course of preparation of the current minireview.

\section{Disclosure of conflict of interest}

There is no conflict of interest.

\section{References}

[1] Song Z, Xu Y, Bao L, Zhang L, Yu P, Qu Y, Zhu H, Zhao W, Han Y, Qin C. From SARS to MERS, Thrusting Coronaviruses into the Spotlight. Viruses. 2019; 11(1): 59.

[2] Yin Y, Wunderink RG. MERS, SARS and other coronaviruses as causes of pneumonia. Respirology. 2018; 23: 130137.

[3] Zhong NS, Zheng BJ, Li YM, Poon LL, Xie ZH, Chan KH Li PH, Tan SY, Chang Q, Xie JP, et al. Epidemiology and cause of severe acute respiratory syndrome (SARS) in Guangdong, People's Republic of China, in February, 2003. Lancet. 2003; 362: 1353-1358.

[4] De Wit, E, van Doremalen N, Falzarano D, Munster VJ. SARS and MERS: Recent insights into emerging coronaviruses. Nat. Rev. Microbiol. 2016; 14: 523-534.

[5] World Health Organization. WHO Guidelines for the Global Surveillance of Severe Acute Respiratory Syndrome (SARS). Updated Recommendations. October 2004.

[6] Arabi YM, Arifi AA, Balkhy HH, Najm H, Aldawood AS, Ghabashi A, Hawa H Alothman A, Khaldi A, Al RB. Clinical course and outcomes of critically ill patients with Middle East respiratory syndrome coronavirus infection. Ann. Intern. Med. 2014; 160: 389-397.

[7] Al-Abdallat MM, Payne DC, Alqasrawi S, Rha B, Tohme RA, Abedi GR, Al NM, Iblan I, Jarour N, Farag NH, et al. Hospital-associated outbreak of Middle East respiratory syndrome coronavirus: A serologic, epidemiologic, and clinical description. Clin. Infect. Dis. 2014; 59: 1225-1233.

[8] Zumla A, Hui DS, Perlman S. Middle East respiratory syndrome. Lancet. 2015; 386: 995-1007. 